\title{
PENGEMBANGAN E-BOOK TEORI EKONOMI MIKRO PADA PEMBELAJARAN BERBASIS BLANDID LEARNING PROGRAM STUDI PENDIDIKAN EKONOMI IKIP BUDI UTOMO MALANG
}

\author{
Novi Eko Prasetyo ${ }^{1}$, Miftah Rakhmadian ${ }^{2}$, Titik Purwati $^{3}$ \\ 1,2,3Fakultas Ilmu Sosial dan Humaniora, IKIP Budi Utomo Malang \\ email: enopi79@gmail.com \\ email: miftahrdian@gmail.com \\ email: titikpurwati62@gmail.com
}

\begin{abstract}
The micro-economics e-book is one of source of learning for students of economics education program of IKIP Budi Utomo, Malang. The purpose of this e-book is to reconstruct the concepts between the theory and practice presented in each subject matter. The research method used in this research is research and development. This research use the Instructional Design Dick and Carey model. This ebook material consists of 7 subject matters. The results of this study showed that as many as 57 students selected to conduct the assessment gave a $96 \%$ value with "excellent" criteria. In the assessment of material experts using a linear scale of 1 to 5, this e-book received a score of 5 in the "very good" category, while the results of the assessment of media experts using a linear scale of 1 to 5 received a score of 4 in the "feasible" category.
\end{abstract}

Keywords: microeconomics e-book, blanded learning

Abstrak. E-book ilmu ekonomi mikro merupakan salah satu sumber belajar bagi mahasiswa program studi pendidikan ekonomi IKIP Budi Utomo Malang. Tujuan e-book ini adalah untuk merekonstruksi konsep antara teori dan praktek yang disajikan dalam setiap pokok bahasan materi. Metode penelitian yang digunakan dalam penelitian ini adalah penelitian dan pengembangan. Penelitian ini menggunakan model adalah Instructional Design Dick and Carey. Materi e-book ini terdiri dari 7 pokok pembahasan. Hasil penelitian ini menunjukkan sebanyak 57 mahasiswa yang dipilih untuk melakukan penilaian memberikan nilali 96\% dengan kreteria "sangat baik". Pada penilaian dari ahli materi dengan menggunakan skala linier 1s/d 5, e-book ini memperoleh nilai 5 dengan kategori "sangat baik", sedangkan hasil penilaian dari ahli media menggunakan skala linier 1 s/d 5 mendapatkan nilai 4 dengan kategori "layak".

Kata kunci: e-book ekonomi mikro, blanded learning.

\section{PENDAHULUAN}

Indonesia adalah negara kepulauan terbesar di dunia yang terdiri dari 13.466 pulau dan Indonesia adalah negara berpenduduk terbesar keempat di dunia tetapi kualitas pendidikan di Indonesia masih sangat memprihatinkan, ini di buktikan dengan peringkat Indeks Pengembangan Manusia (Human Development Index) Indonesia 2018 menduduki peringkat ke 116 dan masuk ke dalam Medium Human Development (UNESCO, 2018), Artinya adalah kualitas Pendidikan di Indonesia harus ditingkatkan lagi dan harus disesuaikan dengan perkembangan zaman.
Perkembangan teknologi berdampak pada pembelajaran, pengajaran dan penelitian dalam dunia Pendidikan (L. Johnson dkk; 2016). Pemanfaatan teknologi akan mewujudkan terciptanya pendidikan yang memudahkan dan menyenangkan, berita media massa, semua kegiatan penunjang kerja dapat di akses dengan mudah via smartphone. Pengguna internet sudah mencapai 88 juta orang dan diperkirakan pada tahun 2018 akan mencapai 100 juta orang (Gfk, 2016).

Gfk adalah sebuah lembaga riset pasar terkemuka di Indonesia dan salah satu perusahaan riset pasar terbesar di dunia, Gfk didirikan pada tahun 1934 dan 
berkantor pusat di Nuremberg, Jerman. The Crossmedia link studi oleh Gfk menunjukkan bahwa hampir $64 \%$ masyarakat jawa adalah penyumbang populasi online di Indonesia. Ada lebih dari setengahnya $(51 \%)$ didominasi oleh anak muda dengan rentan usia berkisar antara 13 s/d 27 tahun (SMP-SMA-Mahasiswa). Melihat fenomena tersebut bahwa peserta didik lebih peka terhadap perkembangan teknologi, maka sudah selayaknya bahwa tenaga pendidik harus dapat mengkreasikan antara kegiatan pembelajaran kontekstual dengan pembelajaran menggunakan teknologi (e-learning). Lingkungan belajar yang mengkombinasikan sesi tatap muka dan aspek online yang efektif diperlukan dalam melakukan pendekatan pedagogis yang inovatif melalui penggunaan teknologi dalam pengajaran dan pembelajaran (Kintu dkk, 2017). Penggunaan teknologi dalam dunia pendidikan akan membuat proses pembelajaran lebih mudah dan menyenangkan, serta dapat menstimulus siswa dalam memahami materi belajar (Prasetyo, 2017)

Melihat banyaknya fenomena tersebut maka perlu adanya pendekatan yang dilakukan dalam memanfaatkan berbagai macam media dan teknologi untuk meningkatkan efektifitas dan fleksibilitas pembelajaran. Pengembangan E-book diharapkan dapat digunakan untuk menunjang proses belajar-mengajar dengan pendekatan blanded learning. E-book disusun berdasarkan materi yang menjadi pembahasan oleh ahli atau penulis yang memahami bidangnya dan memiliki tujuan instruksional tertentu.

Ilmu ekonomi mikro menjadi salah satu matakuliah wajib dan masuk di kriteria matakuliah Keilmuan dan Keterampilan (MKK), kode matakuliah Ilmu ekonomi mikro adalah EKO341. Buku ilmu ekonomi mikro yang selama ini sudah ada pembahasannya masih sangat beragam, belum adanya buku khusus yang membahas secara spesifik tetang Ilmu ekonomi yang sesuai dengan kurikulum Prodi Pendidikan Ekonomi IKIP Budi Utomo, sehingga mahasiswa mengalami kesulitan untuk pemilihan buku acuan. E-book ini diharapkan menjadi media pembelajaran pendidikan ekonomi yang inovatif, kreatif, efektif, menyenangkan serta memudahkan mahasiswa dalam memahami materi dan pengaplikasiannya dalam kehidupan seharihari.

Keunggulan E-book ilmu ekonomi mikro ini adalah setiap pokok pembahasan sesuai dengan kondisi perekonomian Indonesia serta mengacu pada kurikulum Prodi Pendidikan Ekonomi IKIP Budi Utomo Malang.

Matakuliah Ilmu ekonomi mikro merupakan matakuliah wajib pada Program Studi Pendidikan Ekonomi dengan kode EKO341. Secara umum, matakuliah ini dirancang untuk mengkaji ruang lingkup ilmu ekonomi, masalah-masalah dalam bidang ekonomi mikro, hukum permintaan dan penawaran, konsep elastisitas serta perilaku konsumen dan produsen. Dengan mengambil mata kuliah ilmu ekonomi mikro, mahasiswa mempunyai pemahaman mengenai konsep dasar Ilmu ekonomi mikro sehingga dapat mengkaji secara mendalam permasalahan-permasalahan yang berkaitan dengan ekonomi mikro. Matakuliah ilmu ekonomi mikro ini juga sebagai dasar untuk menempuh matakuliah selanjutnya yaitu mikro lanjut. Materi yang akan disajikan dalam E-book Ilmu ekonomi mikro antara lain: konsep ilmu ekonomi, maslah-maslah ilmu ekonomi mikro, permintaan dan penawaran, pasar serta teori produksi dan biaya.

\section{Blended Learning}

Blended: campuran, kombinasi yang baik sedangkan learning: pembelajaran, Pengetahuan. Blended Learning adalah 
proses pembelajaran yang mengkombinasikan antara pembelajaran online dengan offline. Blended learning merupakan terobosan terkini dalam dunia pengajaran. Blended learning merupakan metodologi pengajaran yang menggabungkan pengajaran tatap-muka dengan pengajaran dimediasi komputer. Dengan menggabungkan dua lingkungan pembelajaran yang berbeda tersebut, akan diperoleh keuntungan spesifik yang disediakan oleh masing-masing lingkungan. Menggabungkan keduanya tentu saja akan memberikan akses lebih besar terhadap pengalaman pembelajaran yang maju serta akan bisa menghemat biaya. Blended learning mampu meningkatkan kemampuan mahasiswa dengan cara memberikan pemahaman serta pelatihan materi pembelajaran. (Isti'anah, 2017).

Blended learning merupakan campuran conventional learning dengan virtual learning. Conventional learning merupakan pembelajaran tatap muka yang lazim dilakukan di kelas, sedangkan virtual learning merupakan pembelajaran dengan memanfaatkan jaringan internet, dimana dosen / guru tidak bertemu langsungdengan mahasiswa di kelas akan tetapi berinteraksi melalui jaringan maya. Tujuan blended learning adalah untuk mensintesis pembelajaran tatap muka dan pembelajaran berbasis online menjadi satu campuran yang terintegrasi sehingga dapat menciptakan dampak yang tinggi, efisien dan menarik. blended learning mengintegrasikan pembelajaran yang menggunakan teknologi online dengan pembelajaran tradisional (Thorne, 2003). Blended learning dapat berjalan dengan efektif jika guru dapat mendesain pembelajaran serta memberikan pengalaman yang berbeda dibandingkan dengan pembelajaran tradisional (Jeffrey dkk, 2014).
Blended learning adalah sintesis dari beberapa komponen yang meliputi instructor-led learning (pembelajaran tatap muka dalam kelas fisik), istructor-led elearning (pembelajaran yang dipimpin instruktur melalui media elektronik), dan self-study e-learning (belajar mandiri melalui media elektronik). Berikut ini adalah penjelasan dari masing-masing komponen.

\section{Instructor-Led Learning}

Instructor-led learning mengacu pada proses pembelajaran yang terjadi dalam sebuah kelas fisik, dengan instruktur (guru, dosen, pelatih) melakukan proses pembelajaran pada sekelompok peserta dalam suatu kegiatan tatap muka. Termasuk didalamnya berbagai metode pembelajaran seperti diskusi kelompok, presentasi, demonstrasi, permainan, dan simulasi. Pembelajaran dalam kelas ini secara luas dianggap sebagai bentuk yang paling diterima dalam berbagai organisasi.

\section{Instructor-Led e-Learning}

E-learning adalah suatu pembelajaran di mana metode penyampaian materi pembelajaran disampaikan melalui intranet, internet, media audio video teknologi, dan / atau CD-ROM.

\section{Self-Study e-Learning}

Self-Study e-Learning (juga dikenal sebagai asynchronous elearning) adalah pembelajaran elektronik yang umumnya dilakukan oleh peserta didik tanpa instruktur dan pada waktu yang mereka tentukan sendiri. Yang membedakan dengan instructor-led e- Learning adalah ketidakberadaan instruktur.

\section{METODE PENELITIAN}

Jenis penelitian yang digunakan dalam penelitian ini adalah penelitian pengembangan (Research and 
Development). Penelitian pengembangan merupakan penelitian yang menghasilkan produk yang telah diuji keefektifannya (Sugiyono, 2008). Penggunaan metode Research and Development dalam penelitian ini bermaksut untuk mengembangkan E-book pada mata kuliah Ilmu ekonomi mikro di IKIP Budi Utomo Malang. model yang digunakan adalah Instructional Design Dick and Carey.

Lokasi penelitian yang dipilih oleh peneliti yaitu Institut Keguruan dan Ilmu Pendidikan (IKIP) Budi Utomo Malang yang beralamat di Jalan Citandui No. 26 Kota Malang. Tujuan pemilihan lokasi penelitian ini adalah mempermudah peneliti dalam menerapkan E-book pada mata kuliah Ilmu ekonomi mikro Jurusan Pendidikan Ekonomi di IKIP Budi Utomo Malang. Penelitian ini dilaksanakan pada tahun 2019 di Jurusan Pendidikan Ekonomi di IKIP Budi Utomo Malang. Kegiatan pengembangan atau penyusunan E-book Ilmu ekonomi mikro ini, melalui 5 tahapan yaitu:

Pertama, Menetapkan bahan ajar dari matakuliah yang akan dikembangkan. Pada tahap ini, peneliti perlu menetapkan matakuliah apa yang akan dikembangkan oleh peneliti, yang akan digunakan sebagai E-book pada mahasiswa Prodi Pendidikan Ekonomi. Penetapan didasarkan pada belum adanya buku Ilmu ekonomi mikro yang sesuai dengan kurikulum prodi Pendidikan Ekonomi IKIP Budi Utomo.

Kedua, Mengidentifikasi materi yang menjadi pembahasan pada matakuliah ilmu ekonomi mikro. Setelah menentukan matakuliah yang akan dipilih untuk membuat E-book, langkah selanjutnya adalah menetapkan isi atau materi dari Ilmu ekonomi mikro yang sesuai dengan perekonomian Indonesia.

Ketiga, Proses pengembangan, penyusunan dan penulisan E-book. Pada tahap ini ada tujuh langkah yang akan dilakukan, yaitu: (a) mengidentifikasi tujuan pembelajaran, (b) menganalisis tujuan pembelajaran, (c) mengidentifikasi perilaku dan karakteristik mahasiswa, (d) mendesain indikator capaian, (e) mengembangkan butir soal, (f) mengembangkan strategi pem-belajaran, (g) mengembangkan E-book ilmu ekonomi mikro.

Keempat, Tinjauan ahli dan uji coba. Tahapan ini merupakan suatu proses pengumpulan informasi sebagai dasar guna pengambilan keputusan dalam rangka meningkatkan kualitas produk yang dikembangkan. Tinjauan ahli disusun berdasarkan langkah pengembangan yang terdapat pada E-book dan masih berupa draft, yang nantinya akan digunakan untuk pengumpulan data dan penyempurnaan $E$ book lebih lanjut. Dalam pengembangan $E$ book Ilmu ekonomi mikro ini menggunakan tiga tahap kajian atau uji ahli, yaitu: (1) review ahli materi dan ahli rancangan pembelajaran (2) uji coba kelompok kecil atau teman sejawat, serta (3) uji coba lapangan.

Kelima, Revisi E-book ilmu ekonomi mikro. Tahap terakhir ini adalah revisi produk bahan ajar. Hasil yang diperoleh dari uji coba dan review ahli dan uji lapangan, dijadikan dasar dan pedoman dalam perbaikan E-book agar dapat diupayakan menjadi E-book yang memudahkan pemahaman dan penguasaan mahasiswa terhadap materi Ilmu ekonomi mikro.

\section{HASIL DAN PEMBAHASAN}

Hasil dari penelitian pengembangan E-book pengantar ilmu ekonomi mikro ini adalah:

Tahap pertama melakukan observasi awal guna untuk mengetahui kendala serta kebutuhan-kebutuhan apa saja pada kegiatan pembelajaran ekonomi mikro. Berdasarkan hasil analisa, Beberapa 
kendala yang dialami pada proses pembelajaran Ilmu ekonomi mikro adalah pertama, buku Ilmu ekonomi mikro yang sudah ada masih sangat beragam dan belum sesuai dengan kurikulum prodi pendidikan ekonomi, sehingga mahasiswa sulit untuk mencari refrensi yang sesuai. Kedua, mahasiswa prodi pendidikan ekonomi banyak berasal dari pulau Nusa Tenggara sebagian dari mera masih terkendala dengan gaya bahasa, sehingga sangat diperlukan sumber belajar dengan gaya bahasa yang komunikatif serta mudah dipahami oleh mahasiswa. Ketiga, masih minimnya sumber belajar buku elektronik terutama pada materi ilmu ekonomi mikro sehingga perlu dibuatkan E-book agar proses belajar bisa dilakukan dimana saja dan kapan saja.

Ditahap kedua atau tahap desain, peneliti menyusun E-book dengan mempertimbangkan materi atau tema yang akan menjadi pokok bahasan dalam buku ini. Dan materi yang dibahas antara lain; konsep ilmu ekonomi, maslah-maslah ilmu ekonomi mikro, permintaan dan penawaran, pasar serta teori produksi dan biaya. Tahap ketiga yaitu tahap pengembangan, setelah didapatkan materi umum yang akan dibahas maka selanjutnya peneliti menentukan subbab dari tiap-tiap materi yang akan dibahas.

Tabel 1. Materi E-book Ekonomi Mikro

\begin{tabular}{|c|c|c|}
\hline NO & Materi & Indikator \\
\hline 1 & $\begin{array}{l}\text { Ruang lingkup Ilmu } \\
\text { Ekonomi }\end{array}$ & $\begin{array}{ll}\text { - } & \text { Konsep ilmu ekonomi } \\
\text { - } & \text { Ruang lingkup ekonomi mikro } \\
\text { - } & \text { Ciri-ciri ilmu ekonomi mikro } \\
\end{array}$ \\
\hline 2 & $\begin{array}{l}\text { Masalah-masalah dalam } \\
\text { bidang ekonomi mikro }\end{array}$ & $\begin{array}{ll}\text { - } & \text { Permasalahan ekonomi mikro } \\
\text { - } & \text { Cara mengatasi permasalahan dalam bidang } \\
& \text { ekonomi mikro }\end{array}$ \\
\hline 3 & $\begin{array}{l}\text { Mekanisme Pasar dalam } \\
\text { hukum permintaan }\end{array}$ & $\begin{array}{ll}\text { - } & \text { Hukum dan kurva permintaan } \\
\text { - } & \text { Keberlakuan hukum permintaan } \\
\text { - } & \text { Faktor-faktor yang mempengaruhi permintaan } \\
\end{array}$ \\
\hline 4 & $\begin{array}{l}\text { Mekanisme Pasar dalam } \\
\text { hukum penawaran }\end{array}$ & $\begin{array}{ll}\text { - } & \text { Hukum dan kurva penawaran } \\
\text { - } & \text { Keberlakuan hukum penawaran } \\
\text { - } & \text { Faktor-faktor yang mempengaruhi penawaran } \\
\end{array}$ \\
\hline 5 & Bentuk-bentuk pasar & $\begin{array}{ll}\text { - } & \text { Pasar persaingan sempurna } \\
\text { - } & \text { Monopolistik } \\
\text { - } & \text { Monopopoli } \\
\end{array}$ \\
\hline 6 & Teori produksi & $\begin{array}{ll}\text { - } & \text { Teori produksi dengan } 1 \text { faktor perubahan } \\
\text { - } & \text { Teori produksi dengan } 2 \text { faktor perubahan } \\
\end{array}$ \\
\hline 7 & Teori biaya produksi & - $\quad$ Produksi jangka pendek \\
\hline
\end{tabular}


Tahap keempat adalah implementasi, setelah tersusun rancangan penelitian maka dilakukan uji validasi ahli media dan ahli materi. Berdasarkan hasil validasi ahli materi menggunakan skala linier 1 s/d 5 mendapatkan nilai 5 dengan kategori "sangat layak". Uji coba kedua adalah validasi untuk ahli media, berdasarkan hasil uji validasi ahli media menggunakan skala linier $1 \mathrm{~s} / \mathrm{d} 5$ mendapatkan nilai 4 dengan kategori "layak". Uji coba ketiga dilakukan kepada 57 mahasiswa, hasil penilaian dari mahasiswa diperoleh nilai $96 \%$ sehingga diperoleh kriteria bahwa E-book pengantar ilmu ekonomi mikro ini "sangat baik"

Tahap terakhir adalah evaluasi, berdasarkan hasil evaluasi baik itu dari ahli materi, ahli media, dosen dan mahasiswa, terdapat beberapa hal yang menjadi pertimbangan antara lain; 1) gambar atau animasi pada E-book perlu untuk di tambahkan sehingga bisa lebih menarik; 2) materi yang tersedia masih sangat minim dan perlu diperkaya, baik itu refrensi dll.;3) perlu adanya variasi pemberian contoh tugas individu/kelompok.

\section{SIMPULAN}

Berdasarkan hasil validasi ahli materi menggunakan skala linier 1 s.d. 5 mendapatkan nilai 5 dengan kategori "sangat layak". Uji coba kedua adalah validasi untuk ahli media, berdasarkan hasil uji validasi ahli media menggunakan skala linier 1 s.d. 5 mendapatkan nilai 4 dengan kategori "layak". Uji coba ketiga dilakukan kepada 57 mahasiswa, hasil penilaian dari mahasiswa diperoleh nilai $96 \%$ sehingga diperoleh kriteria bahwa E-book pengantar ilmu ekonomi mikro ini "sangat baik".

\section{DAFTAR RUJUKAN}

Gfk. (2016). Smartphone market up 6.6 percent year-on-year in 2016. www.google.com.

Isti'anah, A. (2017). The Effect of Blended Learning to the Students' Achievement in Grammar Class. IJEE (Indonesian Journal of English Education), 4(1), 16-30.

Jeffrey, L. M., Milne, J., Suddaby. G., \& Higgins, A. (2014). Blended learning: How teachers balance the blend of online and classroom components. Journal of Information Technology Education: Research, 13, 121-140.

Johnson, L., Becker, S. A., Cummins, M., Estrada, V., Freeman, A., \& Hall, C. (2016). NMC horizon report: 2016 higher education edition (pp. 1-50). The New Media Consortium.

Kintu, M. J., Zhu, C., \& Kagambe, E. (2017). Blended learning effectiveness: the relationship between student characteristics, design features and outcomes. International Journal of Educational Technology in Higher Education, 14(1), 7.

Prasetyo, N. E. (2017). Model Sekolah dan Kelas Digital Masa Depan.

Sugiyono. (2008). Metode penelitian kuatintatif, kualitatif dan R\&D. Bandung; Alfabeta

Thorne, K. (2003). Blended Learning: How to integrate online andTraditional Learning. London: Kogan Page Limited.

Unesco. 2018. Human Development Index; http://hdr.undp.org/en/composite/HD I 